\title{
Post-industrial landscapes as renaissance locus: the case study research method
}

\author{
L. Loures \\ Faculty of Engineering of Natural Resources, \\ University of Algarve, Portugal \\ Faculty of Architecture, Landscape, and Design, \\ University of Toronto, Canada
}

\begin{abstract}
The fact that several countries are now facing various problems produced by landscapes constructed during the modern period [e.g. industrial revolution], currently in complete physical and functional decadency, contributed to enlarge the negative public perception about these spaces. However, this perception associated with the need to protect the environment has been in the last decades the catalyst to the redevelopment and renaissance of these landscapes. Often in advantageous locations near city centres, situated along waterways, supported by existing infrastructure, and adjacent to residential communities, these landscapes are environmentally impaired assets that need to be returned to productive uses, and reintegrated into the surrounding community.

The reclamation and conservation of these landscapes constitute, additionally, an important cultural objective, which is inherently sustainable in that it encourages the positive re-use of redundant buildings that are part of our industrial and commercial heritage. This paper addresses the urgent need to reclaim these landscapes, influenced both by two different tendencies connected with the abandonment of industrial landscapes: on the one hand, the urban pressure related to the city's administration and stakeholders' will to urbanize those areas and on the other hand, the increasingly public awareness of the necessity to protect industrial heritage. This paper presents an approach based on the case study research method. This approach and the way it is applied in this paper may be empirically described as the research and analysis of several successful post-industrial landscape reclamation design approaches, in order to build a set of design principles that might inform and serve as a basis to the redevelopment of similar landscapes.

Keywords: landscape reclamation, design, heritage, post-industrial land.
\end{abstract}




\section{Introduction}

The history of the contemporaneous city was influenced by the accumulation of different visions, different urban models and mainly by significant changes in consumption and production patterns. The end of the twentieth century has brought a break in the industrial sector and with it an accelerating obsolescence of several industrial landscapes [34]. The entire industrialized world is experiencing similar effects of the restructuring of the global economy, the automation of production processes, and the relocation of industry to areas characterized by low production costs [22]. This "globalisation" of industry had a profound effect on industrial areas all over the world, contributing to the appearance of several derelict and underused post-industrial landscapes [3] that contribute to reduce the development potential and the quality of life [19]. The fact that these landscapes became economically disadvantaged, environmentally degraded and socially distressed through industrial contamination [12] turned clear that reclamation projects should enable the redefinition of these landscapes through community-based, interdisciplinary action that integrates multifunctional longer-term solutions based on cultural, social, economical and ecological objectives. As quoted by Loures and Panagopoulos [26] these landscapes, when reintegrated into urban context, represent a valuable resource to society [26], however, to achieve this objective, new approaches and methodologies are needed.

This paper presents an approach based in the case study research method which as been defended and applied by several authors $[1,15,16,41]$ in different branches of knowledge "including medicine, law, engineering, business, planning, and architecture" [16]. This approach and the way it is applied in this paper may be empirically described as the research and analysis of several successful post-industrial landscape reclamation design approaches, in order to build a set of design principles that might inform and serve as a basis to the redevelopment of landscapes similar to the ones that were analysed. The methodology applied is connected with the "inverted" application of a process named translational research. This process is the one used to bring theoric research discoveries into practice. The inverted application of this process, proposed in this paper means that the practical achievements in design will be brought into theoretic research informing the creation of a methodology which might be applied in similar case studies increasing the quality of design.

\section{Framing the industrial landscape}

Industrialisation promoted significant changes in the landscape: greater densities in urban areas and the urbanisation of the natural and rural environment. The city acquired a new - industrial - face, and a new order [2]. This new landscape was defined by the concentration of industries and by the needs of a growing population, often new workers in a new society who demanded new public services and infra-structures, thus contributing to the image of the typical 20th century settlement. However, over the past decades globalization, 
deindustrialization, industrial relocation and economic (re)conversion has had a profound effect on traditional industrial areas all over the world and produced a vast array of obsolete industrial facilities and the various impacts, which are generated from them [25]. The formal products of the modernist movement have become obsolete, forcing this generation to decide on the disposition of the last generation's industrial environment [25].

In recent years, several researchers have contributed to evaluating, documenting and developing remnants of the industrial society [6], in order to emphasise the necessity of taking post-industrial landscapes into consideration in the planning of the city, considering industrial heritage as a resource and as an integral part of collective identity. The classification of the landscape as industrial implied a qualitative perception in which territory and industrial infrastructures were analyzed from a functional, cultural and historic perspective [37]. In this sense, and according to Borsi [7], the industrial landscape may be defined as "the landscape resultant from a thoughtful and systematic activity of man in the natural or agricultural landscape with the aim of developing industrial activities". This definition enabled the recognition of an entire landscape as a single "element", as opposed to simply recognizing a building, or a group of buildings of an industrial site, allowing the expansion of the conception of industrial preservation to accommodate "recognized patterns of activity in time and place" [29]. The concept of industrial landscape is, in this sense, used to describe and classify the "remnant" materials of the industrial culture in order to attribute them a new meaning [20,21], with the objective of creating a theoretical basis and a practical methodology both for the study and for the intervention in these landscapes, to adapt them to new production systems and new cultural uses.

\section{Why should cultural [industrial] heritage be reclaimed and protected?}

According to Lefebvre [23] "The city precedes the industrialization", and before the city, "...there was the settlement, the shrine, the village; Before the village, the camping site, the shelter, the cave..." [30] and all these structures are now an integral part of our urban heritage. From rural to urban, and now to industrial, the concept of heritage is currently larger than ever. This enlargement is not only thematic; it is also spatial, once its scope changed from the protection of a single monument to the protection of a whole landscape, or even a whole city [31]. Historic areas are progressively coming under threat of new development [36]. The impact of new construction is noticed not only at nationally important sites, but also in local areas, where small changes can be very significant, diminishing landscape character and local distinctiveness. Therefore, new frameworks and strategies are needed to reclaim, protect and highlight our cultural heritage.

The concept of cultural heritage has clearly meant different things to different groups of scholars and the public interested in reclaiming traditions and landscapes - presented as part of shared, remembered pasts [9]. For this reason, the history behind the birth and development of a city (which the post 
industrial landscape is an integral part) should be traced and features revealed in order to retain, amend and transform implicit values. This analysis of society and this understanding of an area lead to a social perception of the kind of place people wish to live in, and to the realisation that the whole city is our 'heritage' $[14,35]$, regardless of whether it is large, small, historic, industrial, old or new. Cultural landscapes give us a sense of place and reveal our relationship with the land over time $[8,13,38,39]$. They are special places that contain aspects of our origin and development through their forms, features, and history of use $[4,18]$. However, the structures of planning and conservation have exercised a powerful influence on the direction and subject matter of heritage, encouraging a definition of resources heavily dependent on landscape features and defining values according to particular criteria. Typically, conservation was introduced as a component of the larger agenda of land-use planning, and this context has served to shape the development of ideas about what heritage could and should be.

\section{Post-industrial landscapes - places for redevelopment}

In a period when the rehabilitation and regeneration of derelict industrial landscapes is increasingly recognised as a proficient tool for urban redevelopment, thus synthesising cultural values with economic opportunities, industry, the source of every evil and every good, has became the true protagonist in the transformation of the city [33]. Nonetheless, it is very usual to find older buildings, characteristic of the industrial civilization, simply abandoned, surviving alongside with recent development areas. To fight this urban and cultural problem, there is a primary basic assumption that should be followed: in order not to "lose this heritage", it is necessary to consider, first, the reasons behind the development of certain industrial landscape, second, the relation of that landscape with its surroundings and, third, its meanings to citizens.

Changes accompanying urban growth often involve the destruction of characteristic built and natural elements, eradicating the physical expression of former indigenous ways of life that are a very important part of people's culture [40]. This fact was particularly evident after the World War II, when industrial landscapes, predominantly in industrialized countries, faced deep transformations that in several cases contributed to its dereliction and to the disappearance of numerous industrial values, commonly known as industrial heritage. This phenomenon, enlarged in the last decades by agglutinated fluxes of urban growth and urban sprawl and by the decline, abandonment and relocation of industrial activity, faced industrial landscape reclamation professionals with a huge dilemma: how to reclaim and develop those derelict landscapes without destroying the architectural and urban heritage? The answer is not simple, and proving it is the high price that many cities have paid for modernisation and development in the name of progress. The expansion of this process, associated with the demolition of numerous industrial buildings, contributed to the elimination of several social, historical and cultural values 
created by the industrial society, with high technical and architectonic interest [24]. Because of the problems generated by early urban rehabilitation efforts of some post-industrial buildings, responsible authorities have been led to pay greater attention to social and cultural dimensions and to making it a priority in their policies. For this reason, protection of the socio-cultural environment and involvement of inhabitants in the process of urban rehabilitation have gradually been recognised as crucial requirements for its success. However, and even if it is more then ever recognized by landscape architects and other planning professionals that these landscapes need to be protected it is still not clear how to protect them and which frameworks and methodologies should be used? [24]

As quoted by Loures [24] the answer to these questions is relatively complex, because, although there are several possible answers to this question; each one includes generally numerous restrictions enabled by the search for profit maximization by private and public sectors. Even if it is recognized that the environmental, economic and social dimensions of the rehabilitation process cannot be dissociated from the heritage dimension, and that the cultural heritage has become a key factor in improving people's surroundings, addressing issues of social cohesion and encouraging economic development, little has been done in order to rehabilitate the industrial buildings and its surrounding landscapes which catalyse years ago the growth and development of the urban settlement [24].

Unlike explanations that tend to become dominant, the reclamation of industrial landscapes is not just a type of insurance against forgetfulness [25]. It is an instrument of social legitimation $[10,11]$ and a strategy to reclaim and valorise a post-industrial site in order to turn it into a multifunctional landscape $[5,17,32]$.

\subsection{The case study approach}

All over the world several critics have analysed post-industrial reclamation projects. However, these analysis are generally realized when the project is already implement (in situ). Analysing a post-industrial landscape reclamation project during the design phase is a completely different task. Understanding that and the need to create better design proposals, this paper presents a group of design principles that informed the creation of specific methodologies applied by several design professionals in post-industrial landscape reclamation projects.

Following the application of the case study approach, several international post-industrial reclamation projects were analysed and the design principles they used highlighted. This particular research aimed not only to address projects with different design typologies but also with different design programs. In order to reduce cultural biases, we tried to select projects from several geographic locations, enabling the creation of a set of principles that was not site specific. According to the idea presented by Loures et al. [27], which suggests that design strategies for post-industrial landscape reclamation may focus different landscape characters, we attempted to select case studies that focused on these different characters (Environmental \& Aesthetic; Socio-Economic; and Historic 
\& Cultural). The set of design principles that will be presented was based in the analysis of the design principles used in the following projects:

- Bio-Remediation Park Design, Sydney, Australia;

Environmental

\& Aesthetic

Social \&

Economic

Historic

\& Cultural
- Don Valley Brick Works, Toronto, Canada;

- Fresh kills parkland, Staten Island, New York, USA;

- Hammarby Sjöstad, Stockholm, Sweden;

- Águas Claras, Belo Horizonte, Brasil;

- Greenwich Peninsula, London, England;

- Lyon Confluence, Lyon, France;

- Millennium Park, Chicago, USA;

- Distillery District, Toronto, Canada;

- Duisburg Nord Landschaftspark, Duisburg, Germany;

- Westergasfabriek, Amsterdam, Netherlands;

- Zhongshan Shipyard Park, Beijing, China.

Although there are several other successful post-industrial landscape reclamation projects, we considered these ones to be representative of thoughtful approaches towards sustainable development. The presented division does not mean that the projects focused exclusively those specific landscape characters. It represents just the character that was considered to be more evident in the proposed design principles. Given that, the design principles adapted from the analysis of the presented case studies are:

- Promote Compatibility - Foment synergies and mitigate conflicts among existing and proposed functions and uses.

- Design for Adaptability and Diversity - promote adaptability through development that can respond to changing social, technological and economic conditions and diversity and choose through a mix of compatible developments and use what works together to create viable places that respond to local needs.

- Protect Character and Context - ensure that development responds to both site and context to create its own character and identity, reinforcing the sense of place and local distinctiveness, identifying key issues in landscape development.

- Promote Compactness - use land more efficiently to reduce environmental impacts and development costs; to reuse previously developed sites or unused buildings and to ensure more compact development that enhances accessibility, affordability, conviviality and a sense of place.

- Promote Renewable Energies and Resource Efficiency - design should maximise the use of renewable energies, minimising environmental demands.

- Design Resilient Landscapes - promote a design that enables conservation and enhance variation within the landscape, emphasising landscape capacity to recover from adverse situations

- Continuity and Ease of Movement - promote the continuity of multifunctional spaces, encouraging the utilization of reclaimed spaces and promoting accessibility and local permeability.

- Design Walkable Environments - design should create places that connect with each other and are easy to move through, putting people before traffic and integrating land uses and transportation systems. 
- Strengthen the Genius Loci - promote and develop the spirit of the place in the landscape by responding to and reinforcing locally distinctive social historical and cultural patterns.

- Control the Investment - design should promote affordable and economically viable solutions, easy to manage and maintain, ensuring long term sustainability.

- Improve the Existing - the qualities of existing urban places should be highlighted, encouraging a distinctive response that arises from and complements it's setting.

- Design for Change - design should be flexible enough to respond to future changes in use, lifestyle and demography.

- Enhance Legibility - promote legibility through redevelopment that provides recognisable ways, intersections and landmarks to help people find their way around and through relevant vistas, well massed with a clear hierarchy of building scale and spaces.

- Create Value - stigmatised ideas about a landscape may be changed and problems may be transformed into opportunities throughout a design that promotes a shift in public perception.

- Promote Multifunctionality and Diversity - ensure that design creates places that have variety and choice through a mixture of different uses, functions and activities.

- Create Connections - places need to be accessible from several locations and be integrated physically and visually with their surroundings.

- Protect the Industrial Heritage - ensure that all redevelopment of industrial buildings and spaces is of a human scale, well detailed and landscaped and uses quality, durable materials appropriate to the locale, maintaining building's identity.

- Emphasise Landmarks - Landmarks such as distinctive buildings, particularly those significant to society should be emphasised and protected.

- Work with and not against the Landscape - design should seek a balance between the natural and man made environment and utilise each site's intrinsic resources.

- Convert Spaces and Reveal the History of the Place - design should promote the retention of older buildings and open spaces of quality and the creation of thoughtful connections between them and new development areas.

- Create Places for People - For places to be well-used and well-loved, they must be safe, comfortable, varied and attractive. They also need to be distinctive, and offer variety, choice and fun. Vibrant places offer opportunities for meeting people; playing in the street and watching the world go by.

- Promote Dynamic Context - dynamic designs are inherently flexible and capable to ensure that future changes can be accommodated - master plans and frameworks that enable adaptation over time are essential.

- Foment Public Participation - with development partners and local planning authority make explicit provision for public participation to ensure that the community can play a role in shaping (re-)development proposals, take ownership of agreed development frameworks and build capacity for sustainable community regeneration. 


\section{Final considerations}

In a demanding society as the one we live in today, post-industrial landscape reclamation projects should not only respect biological diversity, minimize resource dilapidation, preserve the water and nutrients cycles and maintain the quality of the habitats, but also reinforce landscape character taking into consideration the spirit of the place, integrate the pre-industrial existence in the new landscape, and promote the creation of multifunctional resilient landscapes, capable to incorporate change and enhance life's quality. The reclamation projects of derelict industrial areas studied on the present article follow design principles that promote sustainability, reduce negative environmental impacts, and foment economic prosperity, social inclusion and a better quality of life. For this reason it should be emphasized that the interlocking relationship between design and management is a particularly important feature of any design process [28]. Furthermore it is extremely important that new redevelopments in postindustrial landscapes help people to realise that reclaim, restore and give new uses to industrial landscape are indispensable actions to maintain landscape sustainability.

To conclude it is relevant to notice that the application of the design principles, presented in this article, in the reclamation of post-industrial landscapes represents just a planning and design possibility that may contribute to increase the sustainability of the design. Several other planning options may be proposed. Moreover, one should notice that the application of these principles is not a sine qua non equation to the success of any project. Site and context research, analysis and synthesis must be performed, once "no size fits all".

\section{Acknowledgements}

The author would like to acknowledge the financial support from the Fundação para a Ciência e a Tecnologia (FCT) (PhD. Grant SFRH/BD/27900/2006) and the amazing academic environment proportioned by the Faculty of Architecture, Landscape, and Design of the University of Toronto during the time he has been an Invited Researcher with the MLA program.

\section{References}

[1] Agranoff, R, and Beryl A., 1991. The Comparative Case Study Approach in Public Administration. Research in Public Administration 1: 203-231.

[2] Aguilar, I., 1990. El orden industrial de la ciudad. Valencia en la segunda mitad del siglo XIX. Valência: Diputació de Valência.

[3] Antrop, M., 2000a. Background concepts for integrated landscape analysis. Agriculture Ecosystems and Environment, 77:17-28.

[4] Antrop, M., 2000b. Why landscapes of the past are important for the future. Landscape and Urban Planning, 70: 21-34.

[5] Ashworth, G. J., 1994. From History to Heritage - From Heritage to Identity. In: Search of Concepts and Models. Greg Ashworth e P. Larkham 
[orgs.], Building a New Heritage. Tourism, Culture and Identity in the New Europe. Londres and New York: Routledge, 13-30.

[6] Bergeron, G., 1996. Le patrimoine industriel, un nouveau territoire. Paris: Liris.

[7] Borsi, F., 1975. Le paysage de l'industrie. Bruxelles: Archives d'Architecture Moderne.

[8] Cabral, F., 1993. Fundamentos da Arquitectura Paisagista. Lisboa: Instituto da Conservação da Natureza.

[9] Carr, E., 2003. Cultural Landscapes: Theory, Management, Design. Graduate Seminar, Department of Landscape Architecture and Regional Planning. University of Massachusetts. (http://www.umass.edu/history /ph/ph_word/Carrsyllabus.doc - accessed 03 January 2008, 15:04).

[10] Colardelle, M., 1998. Les acteurs de la constituition du patrimoine: travailleurs, amateurs, professionnels. In: Actes des entretiens du patrimoine [Patrimoine et passions identitaires]. Paris: Fayard, 123-135.

[11] Davallon, J., Micoud, A. and Tardy, C., 1997. Vers une évolution de la notion de patrimoine? In: Daniel J. Grange e Dominique.

[12] Department of Environment, 1991. Derelict Land Grant Advice: Derelict Land Grant Policy. London: DoE.

[13] Drury, P., 2002. The historic and cultural dimensions of landscape. In: Heritage and Sust. Development-Naturopa. Belgium: Bietlot - Gilly.

[14] Fadigas, L., 2007. Fundamentos Ambientais do Ordenamento do Território e da Paisagem. Lisboa: Edições Sílabo, Lda.

[15] Francis, M., 1999. A Case Study Method for Landscape Architecture. Washington, D.C.: Landscape Architecture Foundation.

[16] Francis, M., 2001. A Case Study Method for Landscape Architecture. In: Landscape Journal- Design, plan. and manag. of the land. 20:1-19, nr. 1.

[17] Fortuna, C., 1997. Destradicionalização e imagem da cidade - o caso de Évora. In: Fortuna C., Cidade, Cultura e Glob. Oeiras: Celta, 231-257.

[18] Frenchman, D., 1976. Connecting the Past to the Present. Urban Studies and Planning. Msc Thesis, MIT.

[19] Handley, J., 1996. The Post-Industrial Landscape. The Groundwork Foundation, Birmingham.

[20] Hudson, K., 1964. Industrial Archaeology. An Introduction. London: Historical association.

[21] Hudson, K., 1979. Word Industrial Archaeology. Cambridge: Cambridge University Press.

[22] Jameson, F., 1991. Postmodernism or, the Cultural Logic of Late Capitalism. NC: Duke University Press.

[23] Lefebvre, H., 1991. O direito à cidade. São Paulo: Editora Moraes.

[24] Loures, L., 2008. "Industrial Heritage: a gear to redevelopment". Proceedings of the EURAU 08 - Cultural Landscape, 4th European Symposium on Research in Architecture and Urban Design, January 16-19, 2008, Madrid, Spain, pp. 1-7.

[25] Loures, L. and Panagopoulos, T., 2007a. Recovering Derelict Industrial Landscapes in Portugal: Past Interventions and Future Perspectives. 
Proceedings of the Int. Conf. on Energy, Env., Ecosystems \& Sust. Devel., July 24-26, 2007 Agios Nicolaos, Crete, Greece, pp. 116-121.

[26] Loures, L. and Panagopoulos, T., 2007b. From derelict industrial areas towards multifunctional landscapes and urban renaissance. WSEAS Transactions on Environment and Development Vol. 3 (10) 181-188.

[27] Loures, L., Horta, D., Santos, A. and Panagopoulos, T., 2006. Strategies to reclaim derelict industrial areas. WSEAS Transactions on Environment and Development, 2(5): 599-604.

[28] Lyle, J., 1985. Design for Human Ecosystem. New York: Van Nostrand Reinhold, Comp Ltd.

[29] Meinig, D., 1979. The Interpretation of Ordinary Landscapes: Geographical Essays. Oxford: Oxford University Press.

[30] Mumford, L., 1998. A cidade na história: suas origens, transformações e perspectivas. São Paulo: Martins Fontes.

[31] Neyret, R., 2004. Du monument isolé au «tout patrimoine». Géocarrefour, $\mathrm{n}^{\circ} 3,79: 231-237$.

[32] Peixoto, P., 1997. Imagens e usos do património urbano no contexto da globalização. Tese de mestrado em sociologia: FE, Univ. de Coimbra.

[33] Rossi, A., 1982. The Architecture of the City. Cambridge: MIT Press.

[34] Sieverts, T., 2003. Cities without Cities: An Interpretation of the Zwischenstadt. London \& New York: Spon Press.

[35] Storelli, C., 2003. The city as heritage. In: Towns and Sustainable Development - Council of Europe, Naturopa. Belgium: Bietlot - Gilly.

[36] Strike, J., 2003. Architecture in Conservation. Managing development at historic sites. New York: Digital Printing.

[37] Tandy, C., 1979. Industria y paisaje. Madrid: Instituto de Estudios de Administración Local.

[38] Telles, G., 1956. O homem perante a paisagem. Portugal, Cidade Nova, $\mathrm{n}^{\circ} 4$, pp. 240-246.

[39] Telles, G., 1992. Um novo conceito de paisagem global: tradição, confrontos e futuro (Jubilação do Prof. G. R. Telles) Évora: Univ. de Évora.

[40] Whitmore, K., 2003. Cities: our common future. In: Towns and Sustainable Development - Council of Europe, Naturopa. Belgium: Bietlot - Gilly.

[41] Yin, R., 1994. Case Study Research- design and methods. United States of America: Sage Publications, Inc. 